\title{
The Effects of Text and Task on the Listening Scores of Japanese University Students
}

\section{Yo In'nami \\ Ibaraki Prefectural Kukizaki High School}

\section{Introduction}

We often take it for granted that listening is important, but it is interesting to reevaluate its importance. In communicative activities, 45 percent is devoted to listening (Rivers \& Temperley, 1978, cited in Takefuta, 1984, p. 5). In L2 research, listening (input) plays an essential role in current theories of second language acquisition (SLA), such as the information processing model (McLaughlin, Rossman, \& McLeod, 1983). Therefore, it is reasonable to say that listening is very important in our life and also contributes much to present theories of SLA.

However, listening skills, as well as speaking, reading, and writing skills, become tangible only through tests (tasks). ${ }^{1}$ In other words, it is only possible to make inferences about the listening skills by assigning tests, which suggests that obtained test performance is more or less affected by the way we test. Therefore, it is crucial to know what effects tests have on our test performance. This effect is called "test method effect" (Bachman, 1990) or "task characteristics" effect (Bachman \& Palmer, 1996).

Related to task characteristics are many variables such as text, task, voice, pitch tone, intonation, visual stimuli, sex, background knowledge (Rubin, 1994). However, there have been few attempts to see them systematically. The purpose of the current research is to investigate the effects of task characteristics on a listening test in terms of text (argument (ARG) and description (DES)) and task ((multiple choice (MC) and open ended $(\mathrm{OE})$ ) types. These texts and tasks are chosen for their prevalence in language testing.

\section{Literature Review}

Although there are many variables in task characteristics, few systematic analyses have been conducted. An exception is the model of the assessment of a L2 listening comprehension construct proposed by Dunkel, Henning, and Chaudron (1993). Although this model is "tentative" as they claim, it tries to connect the various components of listening comprehension assessments. In this framework, Purpose of Assessment determines all the other variables, under which Tasks and Examinees 
comprise major listening facet dimensions. Tasks is concerned with task characteristics, while Examinees is related to test-taker characteristics. The focus of the current research lies in Tasks, especially in Text Type and Item Type.

\subsection{Task Characteristics Effects}

\subsubsection{Definition of Text Types and Task Types}

Although there has been no agreement on criteria for text classification, most seem to accept that argument (ARG) is associated with grounds, claims, warrants, and backing, and that description (DES) is characterized by scope of description, identify of individual items, and qualities associated with items (e.g., Rost, 1990).

Regarding task types, even a cursory perusal of tasks on tests may reveal that there is a wide spectrum of different kinds of task type, whereby there is a need for taxonomy. Although several attempts have been made (Bennett, Ward, Rock, \& LaHart, 1990, cited in Bennett, 1993), there are still no agreed organizational schemes. In this paper, the following definitions are adopted as a provisional model: (1) Multiple choice (MC) is a test item where the test taker is required to choose the correct option from several given; (2) open ended (OE) is a test item where the test taker is required to construct their own answers in a few words.

\subsection{Task Comparison Between Multiple Choice (MC) and Open Ended (OE)}

It may be useful to discuss the comparison of $\mathrm{MC}$ and $\mathrm{OE}$. Although several approaches may be possible, both tasks are discussed here in terms of test usefulness (Bachman \& Palmer, 1996). It was developed to evaluate the test on the whole: However, since tasks may hold an important position in the test, it may be appropriate to apply this framework to a task analysis. Table 1 shows the characteristics of each task:

Table 1. Comparison of Task Usefulness of MC and OE

\begin{tabular}{lcc}
\hline Usefulness & MC & OE \\
\hline Reliability & Good & Varies \\
Construct validity & Varies & Varies \\
Authenticity & Low & High \\
Interactiveness & Varies & Varies \\
Impact & Negative & Positive \\
Practicality & Good & Varies \\
\hline
\end{tabular}

Note. $\mathrm{MC}=$ multiple choice. $\mathrm{OE}=$ open ended

Regarding reliability pertaining to "consistency of measurement" (Bachman \& Palmer, 1996, p. 19), MC items are usually more reliable than OE items since they have more items. According to Spolsky (1995), there are two major ideologies underlying testing: The pre-scientific approach, and the traditional (empiricist) 
approach (p. 5). The former is represented by OE (to be more correct, essays), while the latter by MC. Since $\mathrm{OE}$ was marked intuitively and subjectively, the results were unreliable. In response to the urgent need to develop more reliable tests, MC was introduced with the larger number of items and thus higher reliability. Although the reliability produced by $\mathrm{OE}$ varies, there have been improvements. Since this is related to construct validity of $\mathrm{OE}$, it is discussed below.

Regarding construct validity, or "meaningfulness and appropriateness of the interpretations that we make on the basis of test scores" (Bachman \& Palmer, p. 21), both tasks seem to have variable construct validity. Construct validation studies of MC showed that MC tests only a fragmentary knowledge (e.g., Bennett \& Ward, 1993), while it measures abilities in accordance with cognitive theory on the Scholastic Aptitude Test (SAT) (Bejar, Embretson, \& Mayer, 1987, cited in Bennett, 1993). However, no other studies but Bejar, et al (1987) that support the construct validity of $\mathrm{MC}$ have been reported. With regard to $\mathrm{OE}$, its construct validity seems to be unclear. If $\mathrm{OE}$ has a low construct validity, test constructors may be able to raise construct validity by textmapping.

In terms of construct validity, direct comparisons of $\mathrm{MC}$ and $\mathrm{OE}$ have been investigated in several works. Ward, Dupree, and Carlson (1987) used the two tests written either in MC or OE with items testing explicit ideas or inference and found the weak evidence of a format factor by an exploratory factor analysis (cited in Bennett, 1993). Van den Bergh (1990) used the MC and OE formats and at the same time administered 32 tests chosen to measure 16 of the semantic factors in Guilford's structure of the intellect (SI) model. It was analyzed by LISREL to see whether the coefficients for the regression of the latent trait for reading comprehension on the latent traits measured by the SI tests were different with test format. The result showed that the test format did not affect the regression coefficients, and thus there was no format effect.

Authenticity refers to the "degree of correspondence of the characteristics of a given language test task to the features of a TLU (target language use) task (Bachman \& Palmer, 1996, p. 23) and favors OE over MC. This is because, first, a real-world problem solving requires skills that are highly integrated and related to conditions of applications (e.g., Glaser, 1988, cited in Bennett, 1993) and, second, a real-world problem is often ill-structured (Frederiksen, 1984) and answers are often not given in the forms of options.

Interactiveness is defined as "the extent and type of involvement of the test taker's individual characteristics in accomplishing a test task", in which the individual characteristics refer to the "test taker's language ability ((1) language knowledge and (2) strategic competence)), (3) topical knowledge, and (4) affective schemata" (Bachman \& Palmer, 1996, p. 25). First, required language knowledge on each task is still unclear, as discussed above in construct validity. Second, in terms of strategic competence, both 
tasks seem to require different strategies for answering. Answers on MC may be more based on test-taking strategies. Third, from the viewpoint of topical knowledge, MC may activate more schemata through item options and facilitate test performance, or if such schemata is unrelated to test answers, they will hinder test performance. Fourth, affective schemata are defined as the "affective or emotional correlates of topical knowledge" (Bachman \& Palmer, 1996, p. 65) and play an important role in goal setting, assessment, and planning in strategic competence, and either ease or debilitate test performance (Bachman \& Palmer, 1996). This relates to test anxiety, for example, and it is reported that high-anxious examinees score better on MC than $\mathrm{OE}$ (Bennett \& Ward, 1993).

In terms of impact, $\mathrm{OE}$ is more preferable to MC. As MC became prevalent, it was criticized for the reasons that it encourages poor attitudes toward learning and incorrect inferences about its purposes (e.g., that there is only one right answer, that the right answer lies in the head of the teacher or test maker, and that the job of the test taker is to get that answer by guessing, if necessary; Shepard, 1991). As MC, hypothetically, measures decomposed abilities, it was even said that MC leads to "multiple-choice teaching" (Smith, 1991, p. 10). As an alternative to MC, OE has been considered to be free of these problems.

When it comes to practicality, MC is better than OE because MC can be machine scored. OE may become more practical if generalizability theory (G-theory) estimates the least needed number of raters to obtain required reliability, thereby decreasing the number of raters.

After the differences between MC and OE are reviewed, it is still not clear how the two tasks differ in the difficulty, which affects listening test performance. Therefore, it is meaningful to compare them.

\subsection{Task Characteristics in L2 Listening}

Research into task characteristics in L2 listening has been limited. However, a few notable studies should be discussed. Shohamy \& Inbar (1991) examined the text and question types and found that less literary texts were easier to understand than more literary texts, that the participants scored better on local-level (e.g., locating details, understanding single words, recognition) items rather than global-level (i.e., synthesizing information, drawing conclusions, and focusing on cause and effect relationships and on inferences) items, and that most test takers who scored correctly on global questions were able to respond to local questions but not vice versa.

Berne (1993) investigated the text (literary and non-literary) and task types and found that the text types affected only items that tested detailed comprehension, and that this difference was observed only on MC. As the author noted, since the text was written to control the effects of background knowledge, the discourse style of the texts may not have been so different. In addition, the listening texts were two to three times 
longer than the recommended length of two to three minutes, which may have tested memory rather than listening proficiency.

However, it is not clear to what extent the results of these studies are to be trusted since they did not report the validity and reliability of the tests. Furthermore, Berne (1993) conducted an item-by-item comparison of the participants' responses to observe item difficulty across the two texts and the two tasks. Although this was done in terms of the presumed skills each item tested, it was unclear on what basis the skills were identified. The current research tries to solve these problems, so that the results can be interpreted with more confidence and accuracy.

\section{Experiment}

\subsection{Research Questions}

The current research addresses the following research questions:

(1) Do text types affect listening test performance?

(2) Do task types affect listening test performance?

(3) If task types affect listening test performance, is this related to listening subskills measured by each item?

\subsection{Method}

\subsubsection{Participants}

The current research involved 79 Japanese EFL college students from two universities.

\subsubsection{Materials}

\subsubsection{CELT}

The listening section from the CELT was used to measure the listening proficiency of the participants. This test was selected because it was considered to be reliable and to have an appropriate difficulty to be able to discriminate among the participants. The test consisted of 50 listening passages in three sections, comprising a total of 50 multiple-choice items. Although all the instructions were originally recorded in English and presented on tape, they were translated into Japanese and typed out by the author to ensure that the participants were able to understand how to answer the questions.

\subsubsection{Listening Tests}

Two tests were adopted from Listening to TOEFL (1989). The important selection criteria were that the tests had texts of a suitable length from different genres, with an appropriate number of items, thus producing both high reliability and validity. The texts were chosen carefully so that their discourse structures would not be identical. As 
a result, two texts were selected: argument (ARG) and description (DES).

Due to students' low listening proficiency, modifications were necessary for adapting the texts for use with the participants. The possible modified parts were identified by the author and a native speaker of English and were changed to suitable expressions using English-English dictionaries. The modified manuscripts were looked at closely several times through discussions before they were used in the experiment. Modified parts were as follows: (1) Long sentences, for example, adverb phrases plus subordinate clauses, (Although $\mathrm{S}+\mathrm{V} \sim, \mathrm{S}+\mathrm{V}$ ) were divided into two sentences $(\mathrm{S}+\mathrm{V}$, but $\mathrm{S}+\mathrm{V}$ ); (2) Expressions that seemed to be culture bound were rewritten to similar expressions that students might have felt more familiar with (good job $\rightarrow$ good at); (3) Difficult words and phrases were redefined with simple words (levitate $\rightarrow$ fly); (4) and discourse markers were inserted to make content structures more explicit (for example, there is a further advantage $\sim$ ).

Both texts were monologues and read by a British native speaker of English. The speech rate was average based on Tauroza and Allison (1990). The texts were first recorded on $\mathrm{MD}$, then rerecorded on a cassette tape, which means that the texts were recorded with high quality.

The original tests were written in four-option multiple-choice questions that were the same as TOEFL. For the current research, multiple choice (MC) was directly used, and open ended $(\mathrm{OE})$ version was a direct correspondence of the $\mathrm{MC}$ version except that all the options were deleted. Further information regarding the texts is listed in Table 2. (See Appendix for the Listening Tests.)

Table 2. Text Specification

\begin{tabular}{lcc}
\hline & ARG & DES \\
\hline Words & 231 & 246 \\
Items & 6 & 5 \\
Average number of & 14.44 & 11.71 \\
$\quad$ Words per T-unit & & \\
$\begin{array}{l}\text { Flesch-Kincaid } \\
\quad \text { Grade Level }\end{array}$ & 8.1 & 6.9 \\
Duration (min, sec) & 1 ' $40^{\prime \prime}$ & $17^{\prime \prime}$ \\
Speech rate (wpm) & 139 & 152 \\
Type/token ratio & 61.47 & 59.35 \\
\hline
\end{tabular}

Note. ARG = argument. $\mathrm{DES}=$ description

In order to shed further light on the nature of task characteristics, each item was examined in terms of measured listening subskills. This was conducted by the author and the two raters using the Listening Subskills Taxonomy List.

The author and the two raters identified the listening subskills tested by each item. All were MA candidates at the University of Tsukuba and had a good command of 
listening proficiency. The Listening Subskills Taxonomy List was adapted from Brindley (1997). (See In'nami (2001) for the Listening Subskills Taxonomy List.) The raters were presented the List and asked to observe it critically and whether there were any listening subskills that should be added, deleted, and/or revised in the List. No changes were made. Since this classification process took place individually, the two raters were unable to exchange their opinions with each other regarding the List.

In specifying the listening subskills for each item, minimum and most related information to reach correct answers was emphasized to avoid individual differences in test taking. The Listening Tests were administered to the raters individually in the same way as the actual experiment. They listened to the passages twice: first to the whole passage while answering the tasks, and second to the passage section by section. The raters identified the subskill(s) that they thought each item measured and specify, if any, the essential subskills involved that were not on the List.

The results showed little agreements among the three raters. Since the number of raters was very small, the subskills that all the raters specified were selected for further analysis. Identified subskills were the same across the task types. The results are shown in Table 3. (See In'nami (2001) for subskills ratings for all items.)

Table 3. Subskills Specification on Each Item

\begin{tabular}{lcc}
\hline Text & Item & Measured Listening Subskill(s) \\
\hline ARG & Q1 & Identifying the topic \\
& Q2 & Identifying key vocabulary items \\
& Q3 & Identifying key vocabulary items \\
& Q4 & Identifying key vocabulary items \\
& Q5 & Identifying key vocabulary items \\
DES & Q6 & Identifying key vocabulary items \\
& Q1 & Identifying the topic, and \\
& & Identifying key vocabulary items \\
& Q2 & Distinguishing main ideas from supporting details, and \\
& Q3 & Identifying key vocabulary items \\
& Identifying key vocabulary items \\
& Q5 & Identifying key vocabulary items \\
& Identifying key vocabulary items
\end{tabular}

Note. ARG $=$ argument. $\mathrm{DES}=$ description

\subsubsection{Procedures}

\subsubsection{Research Design}

The pilot study was administered to check whether the Listening Tests were of an appropriate difficulty, and whether test instructions were suitable for the participants. A few students who were not included as participants in this study were asked to answer each set of questions. Since no students obtained perfect or zero scores, the Tests were considered to be appropriate. Since the number of test takers was so small, 
no statistical analyses were conducted. It was also ensured that test instructions were appropriate.

After the CELT was conducted, the participants were divided into two groups based on the scores. ${ }^{2}$ The result of a $t$ test showed that the two groups were homogeneous in terms of listening proficiency, $t(77)=0.06, p>.05$. The number of the participants in Group 1 was 36, in Group 2, 43.

The experiment spanned a three-week period as illustrated in Table 4.

Table 4. Experiment Procedure

\begin{tabular}{llcc}
\hline Week 1 & & \multicolumn{2}{c}{ CELT } \\
\hline & & $\begin{array}{c}\text { Group 1 } \\
(n=36)\end{array}$ & $\begin{array}{c}\text { Group 2 } \\
(n=43)\end{array}$ \\
\hline Week 2 & ARG & MC & OE \\
& DES & OE & MC \\
Week 3 & DES & MC & OE \\
& ARG & OE & MC \\
\hline
\end{tabular}

Note. $\mathrm{ARG}=$ argument. $\mathrm{DES}=$ description. $\mathrm{MC}=$ multiple choice. $\mathrm{OE}=$ open ended.

In Week 1 CELT was given to students, and in Week 2 and 3 the study was conducted. All tests were administered, separated by a one-week interval. The order of tasks was counterbalanced between the two groups, while the order of text across weeks. There were, therefore, four different experiment conditions: argument multiple choice (ARGMC); argument open ended (ARGOE); description multiple choice (DESMC); and description open ended (DESOE). The data gathered over the two weeks was combined into these four experimental condition cells.

At the time of testing, two types of packets containing an assessment task were distributed to each group. Participants were given two minutes to examine the test items, a period assessed as reasonable in a pilot run of the procedure. This was done as a pre-listening activity to help subjects focus their listening and to indicate to them the purpose of listening (Brown \& Yule, 1983). The tape was played twice, separated by a one-minute answer period, to reduce the influences of note-taking skills. If the participants are given a second chance for listening, even poor note takers will perform better, so that there can be little influence of note-taking strategies on text and task. After the listening, two minutes were provided to answer the questions. Since the tests were not meant to be memory tests, the participants were allowed to take notes, look at the questions, and write down answers while listening. This procedure was repeated for every test.

The participants were advised to answer every item by making guesses based on partial knowledge. If they were completely lost and had no idea of the correct answer, they were encouraged to eliminate as many incorrect options as they were able to, and 
then guess from among those remaining options (Bachman \& Palmer 1996, p. 205).

For OE questions, the participants were allowed to write answers either in Japanese or in English to exclude interference from writing ability.

\subsubsection{Scoring Procedures}

$\mathrm{OE}$ question was scored using an acceptable response list showing a range of acceptable to incorrect answers. This was established by the author and then revised through a discussion with a native speaker of English. Any discrepancies were discussed, and both acceptable and unacceptable responses were drawn up by the author. Thus, it was assumed that our scoring list was of relatively high validity.

The evaluation was done regardless of grammatical and/or spelling mistakes, and judged to be correct if they contained keywords or keyphrases that appeared on the list. For example, the correct answer for Question 1 of ARGOE had to include at least one of the following keywords: maglev (マグレブ), train (列車、電車), transportation (輸送、輸 送手段、交通、交通手段、移動、移動手段), high-speed train (早い列車、高速列車). The answers were rated as either right or wrong.

The tests were rated first by the author, and then by another rater. The interrater reliability was .93 on ARG and .94 on DES.

\subsubsection{Data Analyses}

Research Question (1) and (2) will be addressed by $2 \times 2$ (text $\times$ task) repeated analysis of variance (ANOVA), and (3) will be handled by Wilcoxon Signed Ranks test.

\section{Results}

All statistical analyses were performed by SPSS (SPSS Inc, 1998) Base $9.0 \mathrm{E}$., as well as ITEMAN (Assessment Systems Corporation, 1995) 3.50.

Before the analysis, Question 5 on argument multiple choice (ARGMC) was excluded since it had shown the low point-biserial correlation coefficient of .02. This may be because the most participants failed to grasp the phrase "wear and tear" in the text. The corresponding Question 5 on argument open ended (ARGOE) was excluded as well from the subsequent analysis.

\subsection{CELT}

The results of the CELT are shown below.

Table 5. Descriptive Statistics of CELT

\begin{tabular}{cccccccc}
\hline $\mathrm{N}$ & Mean & SD & Skewness & Kurtosis & Minimum & Maximum & Total \\
\hline 79 & 24.63 & 4.53 & 0.10 & -0.87 & 16 & 33 & 50 \\
\hline
\end{tabular}

Note. Cronbach's $\alpha=.54$. 
The CELT produced the moderate reliability of .54, which was low from the arbitrary but conventional standard of seeing the reliability of .70 or above as acceptable. Thus, the instability of the test scores may have affected the classification of the participants into two homogeneous groups in terms of listening proficiency. The moderate reliability must have resulted from the fact that the participants' listening proficiency was very homogenous, as will be discussed in Section 5.3.

\subsection{Listening Tests}

\subsubsection{Validity and Reliability}

Descriptive statistics for each test are shown in Table 6.

Table 6. Descriptive Statistics of Listening Tests

\begin{tabular}{lcccccccc}
\hline & $\mathrm{N}$ & Mean & SD & Skewness & Kurtosis & Minimum & Maximum & Total \\
\hline ARGMC & 79 & 3.53 & 1.20 & -0.77 & 0.17 & 0 & 5 & 5 \\
ARGOE & 79 & 1.94 & 1.32 & 0.60 & -0.45 & 0 & 5 & 5 \\
DESMC & 79 & 3.38 & 1.22 & -0.77 & 0.58 & 0 & 5 & 5 \\
DESOE & 79 & 2.27 & 1.50 & 0.19 & -0.08 & 0 & 5 & 5 \\
\hline
\end{tabular}

Note. ARGMC = argument multiple choice; ARGOE = argument open ended. DESMC = description multiple choice. DESOE = description open ended.

Regarding the validity and reliability of Listening Tests, the construct validity of each Listening Test was verified by concurrent validity, and the reliabilities of each Listening Test were calculated, as shown in Table 7.

Table 7. Validity and Reliability of Listening Tests

\begin{tabular}{lccc}
\hline & $\begin{array}{c}\text { Concurrent validity } \\
\text { with CELT } \\
\text { (corrected for } \\
\text { attenuation) }\end{array}$ & $\begin{array}{c}\text { Concurrent validity } \\
\text { with TOEFL reading } \\
\text { (corrected for } \\
\text { attenuation) }\end{array}$ & Cronbach's $\alpha$ \\
\hline ARGMC & $.28^{\star *}(.62)$ & $-.20(-.67)$ & .38 \\
ARGOE & $.42^{\star *}(.74)$ & $-.24(-.63)$ & .59 \\
DESMC & $.29^{*}(.57)$ & $-.08(-.26)$ & .46 \\
DESOE & $.28^{*}(.49)$ & $-.08(-.21)$ & .60 \\
\hline
\end{tabular}

Note. TOEFL reading (3 passages, 15 items in total) $\alpha=.21 ; \mathrm{N}=52 .{ }^{*} p<.05 .{ }^{* *} p$ $<.01$.

The concurrent validity of the Listening Tests and CELT was assessed by correlating and attenuating those scores for correction. The obtained correlation coefficients showed that there were moderate to high concurrent validity between each Listening Test and CELT. At the same time, the concurrent validity of each Listening Tests and the TOEFL Reading Section was assessed by correlating and attenuating those scores for correction. ${ }^{3}$ This was based on the theory of a multitrait-multimethod analysis that 
"tests that are related to each other will show higher intercorrelations (convergent validity) than tests that are not related to each other (divergent validity)" (Alderson, Clapham, \& Wall, 1995, p. 186). Thus, if each Listening Test had good construct validity, they would show higher correlations with CELT than with the reading test. It was found that the Tests had higher correlations with CELT than with the TOEFL reading test. Thus, it was reasonable to say that Listening Tests had enough construct validity.

The reliability was examined by Cronbach's $\alpha$. Cronbach's $\alpha$ showed that each Test demonstrated the moderate reliabilities ranging from .38 to .60 . The reliabilities were not high but moderate, since reliability is a function of the number of items and test takers. If these moderate reliabilities come from the small number of items and are considered to be a problem, a generalizability study (G-study) would be a productive course.

In addition, $\mathrm{OE}$ was more reliable than $\mathrm{MC}$ with the same number of items on both texts. This was unexpected since $\mathrm{MC}$ items are usually more reliable than $\mathrm{OE}$ items. This may be because of the greater variance in the $\mathrm{OE}$ tests.

\subsection{Task Characteristics Effects}

\subsubsection{Task Characteristics Effects on Listening Proficiency}

The effects of task characteristics were analyzed by $2 \times 2$ (text $\times$ task) repeated analysis of variance (ANOVA). The results were shown in Table 8.

Table $8.2 \times 2$ (text $\times$ task) repeated ANOVA

\begin{tabular}{lccccc}
\hline & SS & df & $\begin{array}{c}\text { Mean } \\
\text { Square }\end{array}$ & $F$ & Sig. \\
\hline Text & 0.62 & 1 & 0.62 & 0.53 & 0.469 \\
Task & 144.92 & 1 & 144.92 & 128.34 & 0.000 \\
Text * Task & 4.57 & 1 & 4.57 & 5.45 & 0.022 \\
Error (Text * Task) & 65.43 & 78 & 0.84 & & \\
\hline
\end{tabular}

The results showed that there was an interaction between texts and tasks, $F(1,78)=$ $5.45, p<.05$. Therefore, the data was decomposed into the following data sets and analyzed one by one: MC and OE on ARG; MC and OE on DES; ARG and DES on MC; ARG and DES on OE. They are shown in Table 9. 
Table 9. Interaction of Texts and Tasks

\begin{tabular}{lccc}
\hline & MC & OE & Sig. \\
\hline ARG & 3.53 & 1.94 & $t(78)=10.77, p<.001$ \\
DES & 3.38 & 2.27 & $t(78)=6.67, p<.001$ \\
\hline & ARG & DES & \\
\hline MC & 3.53 & 3.38 & $t(78)=1.01, p>.05$ \\
OE & 1.94 & 2.27 & $t(78)=-1.96, p>.05$ \\
\hline
\end{tabular}

Note. The means of each test was reported above in Table 6 .

There was a significant effect of task, $t(78)=10.77, p<.001, t(78)=6.67, p<.001$; However, there was no effect of text, $t(78)=1.01, p>.05, t(78)=-1.96, p>.05$. Although no main effects were shown in ARG and DES on OE, the obtained $p$ value was .053 and showed the trend: ARGOE was more difficult than DESOE.

\subsubsection{Item-level Analysis}

The result of the task effects indicated that the task as a whole produced a significant difference. In order to identify the exact parts of the task to which the effects of task were attributable, an item-level analysis was conducted using Wilcoxon Signed Ranks test. The results are shown in Table 10.

Table 10. Item-level Analysis of Task Effects by Wilcoxon Signed Ranks Test

\begin{tabular}{|c|c|c|c|c|c|}
\hline & ARGOE 1-MC & 1 ARGOE2-MC2 & 2 ARGOE3-MC & 3 ARGOE4-MC & C4 ARGOE6-MC6 \\
\hline$z$ & $-2.07^{\star}$ & $-5.21^{* * *}$ & $-5.98^{* * *}$ & $-5.58^{* * \star}$ & $-5.49 * * *$ \\
\hline & DESOE1-MC1 D & DESOE2-MC2 D & DESOE3-MC3 & DESOE4-MC4 & DESOE5-MC5 \\
\hline & $-6.14^{\star * \star}$ & -0.31 & -1.89 & $-2.27^{*}$ & $-4.20 * * *$ \\
\hline
\end{tabular}

The results showed that except between DESOE2 and MC2 and between DESOE3 and MC3 there were significant differences between the tasks.

\subsection{Task Characteristics Effects}

\section{Discussion}

\subsubsection{Analysis of Research Question 1: Do text types affect listening test performance?}

The results by an analysis of variance (ANOVA) showed the trend $(p=.053)$ that argument open ended (ARGOE) was more difficult than description open ended (DESOE). To put it another way, the effect of text was found only when the task was OE. In other words, multiple choice (MC) seemed to be insensitive to text types. Therefore, it may be reasonable to say that overall results showed that there were no effects of text types, though there was a trend that ARGOE was more difficult than DESOE. 


\subsubsection{Analysis of Research Question 2: Do task types affect listening test performance?} and Research Question 3: If task types affect listening test performance, is this related to listening subskills measured by each item?

Research Question 2 and 3 are closely related to each other and thus discussed together. The analysis by ANOVA showed that task affected listening performance. Specifically, MC yielded higher scores than OE on both ARG and DES. This result was consistent with the past research findings by Shohamy (1984) and Wolf (1993) in L2 reading. The current research went a step further and investigated where this task effect came in terms of measured ability on each item. The analysis by Wilcoxon Signed Ranks test showed that the task effects were seen on every item except between DESOE2 and MC2 and between DESOE3 and MC3. Although it is not clear why no effects were found between these items, the results suggested that the task effects emerged when the item tested the skill of identifying the topic and the skill of identifying key vocabulary items on both texts. In other words, these skills made a difference in tasks regardless of text types of ARG and DES.

\subsection{Implications}

Based on the findings of the current research, the following two implications are made. First, the results of task characteristics effects are useful for test construction. In fact, the test writers can change the difficulty of listening test. For example, there will be no differences in passage difficulty between ARG and DES as long as the task is MC. If the test must be more difficult, the task should be changed into an open-ended one if possible. However, we should keep in mind that since OE is more difficult than $\mathrm{MC}$, it may not be appropriate to measure listening proficiency of less proficient test takers.

Second, the results of Listening Tests showed that OE showed higher reliability than MC with the same number of items on both texts. This suggests that if the test writers want to create a test with higher reliability, $\mathrm{OE}$ may be the choice.

\subsection{Limitations and Future Research}

There are the following limitations and possible directions for future research regarding the current study. First, although the Listening Tests were carefully prepared, it was not clear whether the participants' listening comprehension could be precisely measured with a few questions. In fact, the reliabilities of the MC Listening Tests were rather low. However, due to the practicality, ((i.e., administration time constraints, and the participants' attention span (related to minimize fatigue)), it was difficult to conduct longer listening tests. Also, it was very hard to obtain "natural" listening texts from the same genre. In fact, most listening texts are directly taken from reading texts, resulting in too formal listening passages. Future research should 
use tests that have more test items and passages.

Second, although the listening texts were carefully selected, they seem to belong to the same genre (i.e., problem solving). Therefore, if more distinguished text types had been used, the effects of text must have been observed. When selecting texts, Biber's (1986) text classification will be a useful framework. He proposed the three dimensions on which all speech and writing in English are based: interactive versus edited text, abstract versus situated context, and reported versus immediate style. Furthermore, regarding task selection, Bialystok (1994) specified the two skill components: analysis of linguistic knowledge, and control of linguistic processing. Her point is that all tasks can be mapped on to these two task dimensions. By using these frameworks for text and task selection, more accurate investigation of them and their interaction may be possible.

Third, although the current research examined the task effects from the point of measured listening subskills, several other approaches may be possible. For example, Freedle and Kostin (1996) examined 337 TOEFL MC items and found out that 14 variables accounted for $37 \%$ of the variance in item difficulty over all items. These variables were, for example, "when the necessary information came in the middle of the text, items were harder." In other words, an examination of item difficulty and a content analysis of each text would be informative to further analyze task effects.

Fourth, Listening Subskills List used in the current research has not been established empirically. Therefore, the validity of the List and the identified construct on each item may not be so high. Although the List was based on Rost (1990) and Weir (1993), these works are not investigated empirically either. Therefore, the current List may not have good validity, and there is room for improvement for skill matching on each item.

Finally, the participants' listening proficiency was very homogeneous: There was no statistically significant difference among two classes in University A and one class in University B, Kruskal-Wallis $x^{2}=2.93, p>.05$. Therefore, the results obtained from the current study may only be applied to other subjects of the similar listening proficiency. It will be desirable to include a wider range of the participants and to see whether and how the task characteristic effects differ according to listening proficiency.

\section{Conclusion}

The current research investigated the effects of text and task types on listening performance. The findings of the research are as follows:

(1) Generally, there were no effects of text types on L2 listening comprehension assessment, although argument texts with open-ended tasks tended to be more difficult than those on description texts. 
(2) Multiple-choice tasks were easier than open-ended tasks both on argument and description texts. This was observed when the item tested the skill of identifying the topic and the skill of identifying key vocabulary items on both texts.

Finally, it is hoped that this research has helped contribute to the understanding of task characteristics.

\section{Acknowledgements}

This research is a slightly modified version of part of my MA thesis submitted to the University of Tsukuba. I would like to thank Professor Akihiko Mochizuki for his guidance, Dr. Randy Thrasher for reviewing the paper, Rie Koizumi for her constructive advice, and Tomoaki Yamashita for allowing me to use his data in TOEFL Reading Section.

\section{Notes}

1. In this paper, the term "task" is preferable to the term "test method", following the logic of Bachman \& Palmer (1996): Task describes directly what the test taker is actually presented with and performs in a language test, rather than to an abstract entity; It is more general, and connects more directly to the notion of task as currently used in language acquisition and language teaching (Bachman \& Palmer, 1996, p. 60).

2. It was preferable but not possible to drop items of CELT whose point-biserial correlation coefficients were .25 or below: Because an experiment at University B was conducted after all experiments at University A were completed, items with point-biserial correlation coefficients of .25 or below targeted to the participants in University A might turn out to be quite acceptable with point-biserial correlation coefficients of .25 or above when aimed towards the subjects in University B. Henning (1987) pointed this out that "Correlation magnitude is partly a function of sample size and ability range, so that the point biserial correlation may change for the same item when different samples of examinees are used." (p. 53).

3. Negative correlations between the Listening Tests and the TOEFL reading section were observed. This was inconsistent with the previous findings that there was a moderate ( $r=.67$; Daigaku Eigo Kyouiku Gattsukai Kyoudou Kenkyu Kikaku Iinkai, 1972 , cited in Yoshida, 1984) or a low correlation ( $r=.01$ to.20; Koike, 1993, p.68-72) between listening and reading. Since the TOEFL reading data included the low point-biserial items, they were excluded, and the data was reanalyzed with the remaining four items of point-biserial correlation coefficients of . 20 or above. The result still showed low to moderate nonsignificant negative correlations ((between ARGMC and TOEFL reading $r_{s}=-.07(-.14), p>.05$ : between ARGOE and TOEFL reading $r_{s}=-.25(-.41), p>.05$; between DESMC and TOEFL reading $r_{s}=$ 
$-.05(-.09), p>.05$; between DESOE and TOEFL reading $r_{s}=-.17(-.28), p>$ .05). It was not clear whether this relationship was peculiar to the current data or may also be seen on other tests. It would be worth taking a closer look at the content analysis of the TOEFL reading test.

\section{References}

Alderson, J. C., Clapham, C., \& Wall, D. (1995). Language test construction and evaluation. Cambridge: Cambridge University Press.

Bachman, L. F. (1990). Fundamental considerations in language testing. Oxford: Oxford University Press.

Bachman, L. F., \& Palmer, A. S. (1996). Language testing in practice. Oxford: Oxford University Press.

Bennett, R. E. (1993). On the meanings of constructed response. In R. E. Bennett \& W. C. Ward (Eds.), Construction versus choice in cognitive measurement: Issues in constructed response, performance testing, and portfolio assessment (pp. 1-27). Hillsdale, NJ: Lawrence Erlbaum Associates.

Bennett, R. E., \& Ward, W. C. (Eds.). (1993). Construction versus choice in cognitive measurement: Issues in constructed response, performance testing, and portfolio assessment. Hillsdale, NJ: Lawrence Erlbaum Associates.

Berne, J. E. (1993). The role of text type, assessment task, and target language experience in L2 listening comprehension assessment. Paper presented at the annual meetings of the American Association for Applied Linguistics and the American Association of Teachers of Spanish and Portuguese. (ERIC Document Reproduction Service No. ED 358 737)

Bialystok, E. (1994). Analysis and control in the development of second language proficiency. Studies in Second Language Acquisition, 16, 157-168.

Biber, D. (1986). Spoken and written textual dimensions in English: Resolving the contradictory findings. Language, 62, 384-414.

Brindley, G. (1997). Investigating second language listening ability: listening skills and item difficulty. In G. Brindley \& G. Wigglesworth, (Eds.), Access: Issues in language test design and delivery (pp. 65-85). Sydney: Macquarie University.

Brown, G., \& Yule, G. (1983). Teaching the spoken language. Cambridge: Cambridge University Press.

Dunkel, P., Henning, G., \& Chaudron, C. (1993). The assessment of an L2 listening comprehension construct: A tentative model for test specification and development. Modern Language Journal, 77, 180-191.

Frederiksen, N. (1984). The real test bias: Influences of testing on teaching and learning. American Psychologist, 39, 193-202.

Freedle, R., \& Kostin, I. (1999). Does the text matter in a multiple-choice test of comprehension?: The case for the construct validity of TOEFL's minitalks. 
Language Testing, 16, 2-32.

Harris, D., \& Palmer, A. (1986). Comprehensive English Language Test, Form A. New York: McGraw-Hill.

Henning, G. (1987). A guide to language testing. Boston, MA: Heinle \& Heinle.

In'nami, Y. (2001). The effects of text, task, and test anxiety on the listening scores of Japanese university students. Unpublished master's thesis, University of Tsukuba.

Koike, I. (Ed.). (1993). 『英語のヒアリングとその指導』. 東京:大修館書店.

Listening to TOEFL (4th ed.). (1989). Princeton, NJ: Educational Testing Service.

Mclaughlin, B., Rossman, T., \& McLeod, B. (1983). Second language learning: An information processing perspective. Language Learning, 33, 135-158.

Rost, M. (1990). Listening in language learning. New York: Longman.

Rubin, J. (1994). A review of second language listening comprehension research. Modern Language Journal, 78, 199-221.

Shepard, L. (1991). Interview on assessment issues with Lorrie Shepard. Educational Researcher, 20, 21-23, 27.

Shohamy, E. (1984). Does the testing method make a difference?: The case of reading comprehension. Language Testing, 1, 147-170.

Shohamy, E., \& Inbar, O. (1991). Validation of listening comprehension tests: The effect of text and question type. Language Testing, 8, 23-40.

Smith, M. L. (1991). Put to the test: The effects of external testing on teachers. Educational Researcher, 20, 8-11.

Spolsky, B. (1995). Measured Words. Oxford: Oxford University Press.

Takefuta, Y. (1984).『ヒアリングの行動科学 : 実践的指導と評価への道標』. 東京: 研究社.

Tauroza, S., \& Allison, D. (1990). Speech rates in British English. Applied Linguistics, 11, 90-105.

van den Bergh, H. (1990). On the construct validity of multiple-choice items for reading comprehension. Applied Psychological Measurement, 14, 1-12.

Weir, C. J. (1993). Understanding and developing language tests. London: Prentice Hall.

Wolf, D. (1993). A comparison of assessment tasks used to measure FL reading comprehension. Modern Language Journal, 77, 473-489.

Yoshida, K (Ed.). (1984). 『英語のリスニング』. 東京:大修館書店. 


\section{Appendix}

\section{Listening Tests}

Argument Text

(Bracketed numbers in the passage correspond to one section used in a skill identification.)

(1) I think the United States has an excellent system of transportation, but I do not think it is good at transporting people between cities that are only a few hundred miles away. (2) For example, imagine a person who needs to travel a long distance for work between Detroit and Chicago, or between San Francisco and Los Angeles, places which are called strip cities. He may spend only a short time in the air and spend several hours getting to and from the airport. This situation makes flying almost as time-consuming as driving. (3) Also, airplanes use a lot of their fuel when they take off from the airport. They are not fuel-efficient on short trips. (4) This may change soon. High-speed trains may be an answer. One new plan for such a train is for something called a "maglev", which is a kind of "flying" train. Maglevs will not actually ride directly on the rails used by ordinary trains, but will fly above rails that are magnetically activated. (5) As they do not actually touch the rails, this will mean there will be very little wear and tear on them. (6) There is a further advantage of maglev trains: They will be able to go faster than one hundred fifty miles per hour-at that speed, ordinary trains have trouble staying on the rails. As you can see, maglevs offer exciting possibilities for the future.

Multiple Choice (For open ended, all the options are deleted)

$(*$ answer key)

(1) What is the main topic of the talk?

(A) Saving energy.

(B) A new kind of transportation.*

(C) Strip cities.

(D) Advantages of air transportation over railroads.

(2) What problems faces a person travelling a long distance for a work between strip cities?

(A) A lack of available flights.

(B) Long delays at the airport.

(C) Boredom on long flights.

(D) Long trips to and from airports. *

(3) When are airplanes not fuel-efficient? 

(A) On short trips.*
(B) On long trips.
(C) When flying over cities.
(D) When flying at a high Level.

(4) How does a maglev work?

(A) It uses nuclear energy.

(B) It rests on a cushion of pressurized air.

(C) It flies over magnetically activated rails. ${ }^{*}$

(D) It uses a machine similar to a jet engine.

(5) According to the speaker, what is one advantage of the maglev?

(A) It is more comfortable than an ordinary train.

(B) It doesn't require much rail maintenance. *

(C) It doesn't remain in any station very long.

(D) It carries more passengers than an ordinary train.

(6) What happens to ordinary trains at speed above one hundred fifty miles per hour?

(A) They are subject to fires.

(B) They become less fuel-efficient.

(C) They produce too much noise.

(D) They have trouble staying on the rails.*

Description Text

(1) It's always a pleasure to show visitors the different parts of our newspaper operation. Please come this way. Here you see our printing presses, and you probably notice the smell of the printer's ink. This is where the paper is printed. (2) Printing is a really dirty process because of the black, oil-based ink we use. You've read newspapers and got the black ink all over your hands, and then probably got it on your clothes or on the furniture at home, right? That may change soon, with the use of a different type of ink. Several major daily newspapers are now trying out a new printing process called flexography. (3) This process produces pages that are very clean, and the ink does not come off the newspaper by touching or rubbing. Flexography presses use water-based inks that dry quickly, not like the standard oil-based inks that take much longer to dry. The new flexograph inking process is also simpler and faster than the standard inking process. (4) However, there's one major problem. The ink may dry too quickly, and slow down the machines. It could even stop the presses, so that they won't work right, or it may cause them to break down altogether. If the machines don't work properly, the process will have to be changed and tested again. (5) There's a possibility 
our newspaper will change to the flexograph process sometime soon. In any case, our readers say they prefer the new clean papers... and clean hands.

Multiple choice (For open ended, all the options are deleted)

$\left(^{*}=\right.$ answer key)

(1) Where does this talk take place?

(A) In a department store.

(B) In a mechanic's workshop.

(C) At a newsstand.

(D) In a newspaper pressroom. *

(2) What is the main topic of the talk?

(A) Recent development in news photography.

(B) The effect of water-based ink on standard printing procedures. ${ }^{*}$

(C) The advisability of frequent changes in dry-cleaning methods.

(D) Experimental printing with oil-based inks.

(3) In what way is the flexography process considered better than standard printing?

(A) The newspapers remain thin and flexible.

(B) The presses can print larger sheets of paper.

(C) The ink is fast-drying and clean.*

(D) The ink can be changed and tested again.

(4) According to the speaker, what is a disadvantage of the flexography process?

(A) Presses may get broken with ink.*

(B) Papers get dirty with old ink.

(C) Reporters prefer the standard method.

(D) Machines may need to be oiled daily.

(5) According to the speaker, what advantage is there for people who read newspapers printed by flexography?
(A) Large print.
(B) Smooth pages.
(C) Pleasant smell.
(D) Clean hands.* 